\title{
Mental Health and the COVID-19 Crisis: The Hopes and Concerns for Children as Schools Re-open
}

\author{
Daniela Fontenelle-Tereshchuk ${ }^{1}$ (D)
}

Received: 4 August 2020 / Accepted: 21 September 2020 / Published online: 9 October 2020

(c) Springer Nature B.V. 2020

\begin{abstract}
The COVID-19 crisis has affected everyone, especially elementary school-aged children who might be too young to fully understand the sudden changes in familiar social norms as well as the unprecedented pandemic-induced educational context. This article is based on a case study that explores the perspective of the experiences of ten parents of elementary school children in French Immersion programs from different school boards during the March-June 2020 schools' closure in Alberta. The findings show that parents had a special concern for the mental health of their children during the transition into lockdown and the ramifications of such experiences in the future as students return to school at the start of the academic year under a different climate. This includes adapting to new social norms and a certain apprehension of how school hygiene and safety measures in place will prevent a new coronavirus outbreak in schools.
\end{abstract}

Keywords COVID-19 crisis $\cdot$ Mental health $\cdot$ School $\cdot$ French $\cdot$ Parents

The COVID-19 crisis created a new conceptualization of school where presential learning in schools moved into a new model of homeschooling where children had limited interaction with teachers and classmates, relying on their often overwhelmed busy parents and guardians for learning support.

In Alberta, schools were closed from mid-March to the remainder of the school year and classes moved online. Children in elementary schools were perhaps too young to fully comprehend the reasons why this new reality took place, and the transition and adaptation into this new way of living and receiving an education were emotionally distressing to many families, especially children (American Academy of Pediatrics 2020).

The introduction of new social norms that required social distancing, which strongly recommended keeping two meters apart from other people, impacted access

Daniela Fontenelle-Tereshchuk

Daniela-tereshchuk@ucalgary.ca

1 Werklund School of Education, University of Calgary, Calgary, Canada 
to public areas. Familiar sites for children to play and meet friends such as playgrounds, parks, and the public library were also closed.

This article is based on a case study with ten parents from different school boards in a major city in Alberta, Canada. The study focuses on the perspectives of ten Elementary French Immersion parents on how the current pandemic has affected the education of their children and the burden it has put on them as well, now that they were all suddenly homeschoolers. These parents share their insights on the possible impact of this crisis on the mental health of their children. They also express their hopes and concerns as classes start in schools in the coming Fall.

\section{Literature Review}

In Alberta, Elementary French Immersion schools usually host Kindergarten to Grade 6, and children are approximately between five and eleven years old. French is one of the two official languages spoken in Canada, and there are a number of educational programs that provide student with the opportunity to learn French such as Francophone, French as Second Language and French Immersion programs (Alberta Education 2020b).

The great majority of the elementary school students whose parents participated in this study, with the exception of one student attending the Francophone program, attend French Immersion schools and are expected to "be fluent in French" after finishing the program (Alberta Education 2020b). In French Immersion programs.

French is used as the language of instruction for a significant part of each school day; several or all subjects are taught in French except the English Language Arts course... is intended for a child whose first language is not French. (Alberta Education 2020b).

During the pandemic lockdown, Elementary French Immersion schools were closed affecting many aspects of children's lives. Parents in this study raise their concerns on how such dramatic change may impact these children's mental health.

The World Health Organization (WHO) (2019) defines mental health as "a state of complete physical, mental, and social wellbeing, and not merely the absence of disease or infirmity" (p. 2). WHO (2019) suggests that creating "a safe, effective, timely, efficient, equitable and people-centered" (p. 2) environment is a basic condition in which mental health initiatives flourish.

The overall literature on the importance of schools addressing the mental health of children and its impact on academic success suggests that "schools nursing is well positioned to respond to the need for mental health promotion, illness prevention, and early intervention related to children's mental health" (DeSocio and Hootman 2004, p. 189). They suggest that it is fundamentally important to foresee early mental health issues in children to provide the necessary support and prevent further impact on their school experience and academic success. Children greatly benefit from developing and maintaining good mental health habits and mechanisms to cope with stress (Maller 2009; Maller and Townsend 2006). 
Some literature also suggests concerns underlining the importance of recognizing some of the possible mental health issues children might face as they start a new school year, most likely returning to schools and adapting to new necessary social distancing routines (Statistics Canada 2020; American Academy of Pediatrics 2020; Sick Kids Foundation 2020).

A survey in June 2020 by Statistics Canada (2020) pointed that eighty percent of parents of elementary school children between the ages of four and eleven years old were "most likely to be very or extremely concerned about balancing child-care, schooling and work" (p. 1). This included attending to the "children's behaviours, stress levels, anxiety and emotions" (p. 1). The parents point to problems such as the complex use of screen time, social isolation, a perceived loss in academic progress, and how children's general mental health could have been affected by this pandemic (Statistics Canada 2020).

During the schools' closure technology was widely used to implement 'homeschooling', and facilitate the process of continuing to learn from home with the support of teachers and parents. Several parents were also concerned that the children's use of technology was also impacted by the lack of child-care for working parents during this time (Statistics Canada 2020). According to Holloway et al. (2013) and Livingstone (2019), the use of technology has increased in recent years, especially in developed countries. However, research focused on the complexity of the use of technology among young children is scarce and much needed (Holloway et al. 2013). Holloway et al. (2013) noticed that.

the substantial increase in [technology] usage by very young children has not yet been matched by research exploring the benefits and risks of their online engagement, so there are many gaps in our knowledge (p. 4).

Livingstone (2019) notes that the experiences of children using technology may be influenced by many factors such as age and "partly on his or her resilience and resources to cope with what happens on the Internet" (p. 12), suggesting that parental as well as school support are key to enhance children's online experiences. Additionally, putting measures in place to regulate the use of online content by children, addressing the risks of technology, and age-appropriate content availability and usage at home and in schools are important to utilize the potential benefits of technology (Livingstone 2019). However, Martin (2011) argues that more the two hours daily of screen exposure can lead to mental health issues in young children.

The context in which schools were closed due to the COVID-19 crisis is unprecedented in recent history. The isolation period, when children were away from school and had limited interactions with teachers and friends, might have also impacted their mental health (American Academy of Pediatrics 2020; Sick Kids Foundation 2020). Other studies indicate that social interaction is key to the mental and physical development of young children, suggesting that inadequate social interaction experiences could lead to mental health-related problems such as anxiety and depression (Lacey et al. 2014; Makinodan et al. 2012; Matthews et al. 2015).

In terms of managing the impact of this crisis on children's mental health, other aspects of education can be addressed to improve the learning outcomes 
of children who experienced stressful adversity. Varela et al. (2013) suggest that developing children's social and emotional skills to cope with adversity is an important factor in school success and mental health. Varela et al. (2013) remark that "when teachers implement interventions such as proactive classroom management, interactive teaching methods, cooperative learning techniques, and interpersonal skills instruction, students' positive attitudes and commitment to school significantly increase..." (p. 2).

Ozdemir and Yilmaz (2008) suggest that environment choices in schools are important as they might have an impact on children's mental and physical health as such environments influence their interest in engaging in activities, affecting their performance and attitude towards learning. The American Academy of Pediatrics (2020) and Sick Kids Foundation (2020) provide suggestions on how preventable measures could be implemented as schools re-open, for instance, utilizing outdoor spaces for teaching purposes. Many studies also point to the fact that children's mental health is strengthened by engagement and exposure to natural environments (American Academy of Pediatrics 2020; Gill 2011; Maller 2009; Maller and Townsend 2006; O'Brien and Murray 2007). Gardening, for example, has been taught in many schools at different capacities as weather can be a factor in colder countries. Such practice has shown to improve children's understanding of nutrition (Morris and Zidenberg-Cherr 2002).

Research on the COVID-19 virus is in its early stages or very limited, especially regarding children's susceptibility to infections, possible health-related effects, and the potential role of children as carriers (Wu et al. 2020). Wu et al. (2020) investigate how the coronavirus affects children. Their study shows that out of 74 COVID19 infected children who participate in the study, only 1 child was diagnosed with severe symptoms, another 24 children presented acute upper respiratory tract infection symptoms, 29 children had mild pneumonia symptoms, and the remaining 20 children were asymptomatic. However, these asymptomatic children were carriers of the virus and could potentially spread it. Even though the study suggests that some children did get sick due to catching the coronavirus, there were no fatalities, and all 74 children recovered within 14 days. According to Wu et al. (2020)

The exact reason for the milder nature of the disease in children is still unclear.

One possible explanation is that their immature immune system is less likely to mount an excessive inflammatory response and cytokine storm, as observed in adult patients. Relatively stronger humoral responses in children may also contribute to this youthful resilience. (pp. 6-7)

The American Academy of Pediatrics (2020) recognizes that our understanding of the impact of the COVID-19 crisis on children is evolving but highlights the mental and physical health benefits to children of the in-person interactions nurtured in schools. It suggests that the school lockdown had negative effects on children's health and schools should re-open. However, it strongly recommends the adoption of social distancing norms and a well-thought plan to protect the safety of students, teachers, and the community. Since the pandemic is still unfolding, and in some states in the United States, the number of infections has surged over the summer (John Hopkins University and Medicine 2020), in addition to the fact that 
science has not caught up with the necessary understanding of the complexity of the COVID-19 virus or a vaccine, caution with school re-opening might be at the heart of public debates.

In sum, classes in K-12 schools are scheduled to start in September 2020 in Alberta (Alberta Education 2020a). Although the present pandemic context is uncertain without preventable vaccines or proven effective medication to treat those affected by the virus, and mostly relying on social distancing measures and the use of facemasks, the risk of possible infection outbreaks in schools have added to the stress of many parents. However, a few parents believe that these risks are manageable if schools plan well to address the need for social distancing and hygiene practices (American Academy of Pediatrics 2020; Sick Kids Foundation 2020). Addressing the mental state of children returning to in-person classes is of key importance and strongly recommended in the re-entry plan (American Academy of Pediatrics 2020; Sick Kids Foundation 2020; Statistics Canada 2020).

Gray et al. (2017) argue that "teacher well-being, school climate, and inclusive education all impact student learning" (p. 207). A human-centered approach to schools is important as it addresses different school individuals-students, teachers, parents, and all other school community members, as part of a living and breathing interdependent organism that makes up the school community, who need to have their needs addressed to create and sustain a healthy environment for learning (Fontenelle-Tereshchuk 2020).

\section{Methodology}

This is a case study with ten parents whose children attend elementary school French Immersion programs in one of the three major school boards in Alberta. Case studies are ideal to explore the different and similar nuances of contextualized experiences among participants, providing a broad and meaningful understanding of such complex experiences (Yin 2009). Yin (2009) points to five important components in a case study: "1. The study's question; 2 . Its propositions; 3 . Its unit of analysis; 4. The logic linking the data to the propositions; and 5. The criteria for interpreting the findings" (p. 27), such understanding was key to design this research project's design.

The extensive data was sorted and grouped into color-coded emerging themes in a wallmap format. The study applied mostly qualitative methods to collect the extensive data (Creswell 2012): A structured 8 questions survey, which provided a brief demographic overview of the participants' background; a semi-structured 10 questions individual questionnaire; and a semi-structured 3 questions focus-group interview with the parents. The focus group interview was $40 \mathrm{~min}$ long, via ZOOM, and guided by 3 open-ended questions. It was also audio-recorded and transcribed later. The findings are organized in the form of common themes and sub-themes emerging from the data collection (Creswell 2012).

The study received ethical approval from the Conjoint Faculties Research Ethics Board (CFREB) at the University of Calgary. The study has 10 participant-parents who were recruited through a public research (online) post on the University 
of Calgary website and by networking. The parents accessed the online portal and applied to take part in this research. The ones who met the criteria of being a parent or guardian of a child/children of an elementary school student(s) in one of the French Language programs in Alberta during the recent school closure were selected. French elementary school parents are part of a minority group in Alberta.

\section{Limitations}

This study is significant especially since we are still living with a global pandemic and foresee the possibility of having elementary school students return to a new normal in the schools in Alberta.

There are many unknowns, and due to the participant sample size and context, this study provides only a glimpse into the effect of this crisis. However, it is a significant example of what happened in many Canadian homes. Even though individual contexts might vary, one can relate to a number of the important issues approached here.

\section{Findings}

The ten parents in this case study indicate that the mental health of their children was one of the main concerns they had as the impact of the COVID-19 crisis during the temporary closure of schools from mid-March to the end of June 2020 in Alberta. They elaborate on their perspective on some of the factors they found contributed to the stress and mental health challenges of parents and students during the 'homeschool' process. These parents also provide a number of insightful suggestions on how to move forward as well as their concerns about the future as the schools reopen under uncertain circumstances, and its impact on their children's mental and physical health.

\section{Participants, Themes, and Sub-themes}

In order to maintain confidentiality, we will refer to them by the following pseudonyms: Anni, Carol, Macy, Nate, Jessica, DDM627, KMac B, Gio, Karen, and Ralph. The following parents' brief demographics is based on the survey:

- Anni, a full-time working parent of a child in grade two in the Calgary Catholic School board. She speaks French.

- Carol, a stay-at-home parent of a child in kindergarten in a Francophone school. She speaks French.

- Macy, an unemployed parent of a child in grade two in the Calgary Board of Education. She does not speak French.

- Nate, a full-time working parent of a child in grade six in the Calgary Board of Education. She does not speak French. 
- Jessica, a full-time parent of a child in grade two and another one in grade five in the Calgary Board of Education. She does not speak French.

- DDM627, health-care full-time working parent of a child in grade one and another one in grade four in the Calgary Board of Education. He/she does not speak French.

- KMacB, a full-time working parent of a child in grade one and another child in grade five in the Calgary Board of Education. She does not speak French.

- Gio, an unemployed parent of a child in grade four in the Calgary Board of Education. She does not speak French.

- Karen, a full-time working parent of a child in grade two in the Calgary Board of Education. She speaks French.

- Ralph, a stay-at-home parent of a child in grade two in the Calgary Board of Education. He does not speak French.

It is important to notice that in the context of this study, lack of access to technology was not reported as an issue during the lockdown. This strongly suggests that these children were provided with the technology means they needed to learn from home. The number of children reported in the study are just the ones attending French Elementary schools, and it does not mean that these parents necessarily do not have other children at home. It was also important to know whether or not these parents could speak French because the lesson plan content sent home was mostly in French.

The following themes and sub-themes emerged from the individual questionnaire and focus group interview.

\section{Mental Health: The Transition from School-Based Education into 'Homeschooling'}

The study asked the participants to describe how students' transitioned from schoolbased education to exclusively home-based education or what we will be referred to as 'homeschooling'. The challenges imposed by the sudden changes in social norms due to this world pandemic impacted the mental health of parents and students. During this time, parents had to balance workloads, household chores, and other responsibilities with their new role as a key supporter of this 'homeschooling' model of learning from home, which significantly affected their stress level. These students went through rapid changes in which they had to develop coping mechanisms to make sense of this new social reality. This greatly impacted their routine and social interactions potentially prompting emotional distress and changes in behaviors.

\section{Social Interaction and Mental Health}

Anni explains that "my [her] child felt confused at times, especially early during the pandemic. She missed and continues to miss in-person interaction with the teacher and students" (data extract). 
Carol argues that her child, who had been in kindergarten just for a few months, generally speaking, did well with the transition to learning from home. However, she adds that "the only drawback was the social aspect of not being able to be with her friends and teachers which I consider important as well" (data extract). Macy, another parent in this study, tells us that

My child is socially very active, and it is noticeable that it is hard for him being apart from friends. He has had many sadness periods and crying at night for the loss of friends. So, although progress is being made academically, socially the impact is hard. (data extract)

Nate's child is in grade 6 and will be moving into a new school in September which has made this 'homeschooling' process even more challenging for her. She says that

This abrupt transition has had a negative impact on my child. This has been an emotional time. This has created a great deal of anxiety for her. She is transitioning from elementary to middle school and without a formal end to her elementary world, she is more anxious and even sometimes angry about having to go to a new school. (data extract)

\section{Emotional and Academic Support}

Jessica says that academically her children were fine, since they support each other and "they have a good study desk with a computer and internet and their father is an IT expert" (data extract). However, emotionally "the combination of closed schools, libraries and playgrounds is [was] deeply disturbing to them" (data extract).

DDM627 notes that his/her two children had a different experience as he/she explains that "socially, I can feel their boredom coming out in emotional outbursts, for sure... an inability to "wind down" as well I think was hard on them"(data extract). $\mathrm{KMacB}$, another parent, explains that both parents work full-time, their children needed a lot of support, and the lack of time to support her children associated with the fact neither parents speak French, was a key stress factor for everyone in their household. As she explains

Balancing working from home and helping our 2 elementary children with their school work was very challenging. There were simply not enough hours in the day for us to parent, teach, submit their work and do our career work. This model is unsustainable. (Data extract)

Finally, Karen notes that there was a deficit in academic learning compared to what she believes her child would have learned in school, but her child "adapted relatively well" (data extract). 


\section{Mental Health: Concerns and Hopes for the Future as Schools Re-open}

The study also asked of these participant-parents their concerns and hopes for the future as most elementary schools are scheduled to start in the Fall of 2020.

\section{Schools Reopening}

Anni argues that her main concern is related to the transition of students back to school and the new social distancing norms that students will most likely be subjected to. She argues that

As a parent, I am concerned how these potential restrictions at school will impact my child's mental health and learning process, as well as social development. I think such restrictions will add a lot of anxiety to the learning environment that will be negative for mental wellbeing and learning. It may be very confusing in terms of the curriculum delivery if a blended model will be adapted (some of it in-class, and some - online). The future for school education is very uncertain in terms of new routines. Our kids thrive having a clear and certain routine, they also need to maintain unobstructed (without $2 \mathrm{~m}$ apart) social interaction with peers and when it is not a case, it will have a negative impact. (data extract)

Carol shares the same concerns as Anni regarding the adaptation to the new social norms; however, she adds with respect to her daughter that

Since she is entering into grade 1 in the Fall, she will no doubt be excited to meet new friends and teachers. The social distancing norms will be a big problem for her as she is very social and has a great network of friends at school. I certainly hope that this will not hinder her school experience. (data extract)

$\mathrm{KMacB}$ is concerned about the management of budget cuts associated with a possible increase in classroom sizes and the effect on the social distancing measures in schools. She notes that

One might hope that a public health crisis such as this might have a longlasting positive impact on education. Perhaps in the future, when flu season hits, we won't see it literally move from desk to desk and row to row as it makes its rounds through the classroom if we can reduce class sizes and place a greater focus on hygiene. (data extract)

Ralph suggests that if effective teaching guidelines and protocols are put in place, the adjustment of children back to school will be easier. As he explains, "I do see an adjustment period in September for all children however if proper teaching protocols are taken by teachers children will adjust well". 
Gio suggests that we should be prepared in case this unstable reliance on pandemic conditions persist, and parents have to go through supporting their children's learning again. As she says

I believe we would have to keep in mind that it is extremely necessary to have our attention and efforts focused on our kids learning no matter what. If today we have the school to help us maybe tomorrow we won't so it has to be significantly present in the learning of our children should be our main concern. (data extract)

\section{Parents' Inputs on Pedagogical Practices}

Macy is concerned that

If we go to school half-time, it will impact our kids' education for generations to come. Social distancing for kids is very unnatural and I see this as one of the main issues. If there will be no recess, it will be extremely hard to manage. (data extract)

Macy adds that she hopes that schools will focus on younger children's particular needs and utilize outdoor spaces for teaching as much as possible, taking into consideration weather- related restrictions at times. She remarks

I truly hope that the teachers will find a way to transition as much teaching to outdoor space as possible (especially for younger grades) while we are dealing with the pandemic. There are many examples around the world about mostly outdoor schools, and they are very successful. Rather than eliminating gym classes (which I have heard rumors about), please have gym classes for kids outside. It is possible to be outdoors also in the winter and only stay indoors when it is extremely cold. And there are many history, art, craft, nature, social science and other topics that do not have to be all lectured in classrooms. (data extract)

KMacB agrees with Macy's views on extending the school environment to other available spaces. She argues

I am not in favor of home-based education that even remotely resembles what we had over the past few months. I would much prefer initiatives to free up space (community centres, recreation facilities, etc.) to offer more options for in-person physically distant learning, experimentation with outdoor education options (yes - even in a winter country!), etc. (data extract)

\section{Mental Health and Special Needs}

Nate, Jessica, Karen, and Gio are concerned about the aftermath of the loss in academic skills during the lockdown, and the return to school routine with new social distancing norms after staying at home for months. Nate, in particular, stresses the fact that her child will be attending a new school that makes things more challenging 
to adapt, and Karen worries about "the challenge for our child to go from that limited time back to full-time schoolwork"(data extract).

There was also a concern among parents related to students with special needs, for example, children with Attention Deficit Disorder-ADD and excessive anxiety.

\section{Academic Loss}

$\mathrm{KMacB}$ and Ralph suggest that students will recover from the perceived academic loss during the lockdown, but they will need support. KMacB hopes that mental health and outbreak management will be given priority as children return to schools. She explains that

Supporting mental health will also be important, particularly if physical distancing protocols are to remain in place. We will have children who have been separated from their friends for 6 months who will need some support to remember how to rebuild healthy relationships. The other big factor that is concerning is how the schools will manage outbreaks and zero tolerance for illness. How will these kids have continuity in learning with 14-day isolation requirements at the first sign of any illness for both kids and teachers? (data extract)

$\mathrm{KMacB}$ suggests that the online instructional process during the pandemic was not very effective and that caused a lot of stress in her/his household. She notes that "the instructions were in the Google Classroom for the kid/parents to read and that just does not align with the learning styles of children." (data extract)

\section{Mental Health and 'Too Much' Screen Time}

A last concern for KMacB is "that the students had far too much screen time through the pandemic from school (not to mention the screen time parents gave in to because they needed to work)." (data extract), and the possible impact that it might have on their children's mental health as they return in-person instruction. Jessica adds that her children "watched too much TV, played computer games and wasted days, weeks and months of their valuable time" (data extract). Macy also shows concerns about the use of screen time during the school closure. She remarks

I found my son was having a very difficult time of being alone and not being interacting with friends at all. I guess, we could use a lot of technology but there was very little opportunities to interact with friends as well during that time. (data extract)

To conclude, Anni became emotional and teary as she describes the reaction of her child meeting a friend in the playground after 3 months without seeing her friend in person

I know that my daughter for the first saw her friend at the playground on Saturday and she [pause] as we were walking towards the playground she said: 'I 
don't know if I will recognise * Mary [alias name of the child], maybe by the hair!' [Anni becomes very emotional as tears flow down her cheeks, she had to excuse herself for a short moment to recompose herself] (data extract)

\section{Discussions and Implications}

In Alberta, the number of COVID-19 infections has been low but showing signs of increase throughout the month of July 2020 (Alberta Government 2020). After the partial provincial reopening in June, the number of coronavirus infections has fluctuated, and the province has responded by putting safety measures in place, such as social distancing, and the use of facemasks in public places has become highly recommended or compulsory as of August in Calgary.

Schools will start in the Fall close to normal capacity as the Government of Alberta has decided to proceed with scenario 1- "In-school classes resume (near normal with health measures)" with safety measures in place (Alberta Education 2020a, p. 4). Regardless of whether parents are in favor of or against, the prospect of the re-opening of schools may be a concern, as they are faced with a difficult and stressful decision of balancing the pros and cons of sending their children back to school in the Fall.

One of the main concerns for parents was the mental state of children due to the aftermath of three months learning remotely with very little interaction with teachers or friends as well as these children's adaptation to returning to school under social distancing measures (American Academy of Pediatrics 2020; Sick Kids Foundation 2020; Statistics Canada 2020).

Some parents were concerned with a possible increase and perhaps overuse of technology during the lockdown (Statistics Canada 2020). The accounted time of children's exposure to technology may include the time spent attending classes as schools went online, extra time-allowance given by parents who often had to work without the necessary childcare, and the closure of important places for children's physical and social activities such as playgrounds. Technology has many benefits and it was key to make learning from home possible or easier for the school community during this pandemic. However, overexposure to more than two hours daily of screen time may lead to mental and health problems in children such as sedentarism and depression (Martin 2011).

Other concerns include a perceived content-related academic loss for the students, and the possible challenges anticipated by school re-entry such as re-adaptation to a 6-h strict school schedule, large class sizes, and the complex implementation of hygiene and social distancing measures, especially for elementary school-aged children between the ages of 5 and 11 years old. One of the parents, whose child is in grade five has Attention Deficit Disorder (ADD), is particularly concerned about how schools will financially manage to provide special needs children with the extra help they often require. Another parent of a child on grade six also mentioned how this unusual transition into middle school experienced in the last year of elementary school affected the anxiety level of her child. This might be an indication of how this crisis might have affected children in the last grades of elementary school, in other 
words, students who are approximately 10 or 11 years old. These students could be more independent using technology compared to younger students but in this pandemic context even older students still needed substantial emotional support from parents to progress academically.

The parents' insights suggest some constructive recommendations for schools and especially teachers to facilitate this re-entry of children in schools:

First, parents suggest teachers widely use outdoor spaces and for severe weather days consider community centers and other large public closed-in locations as much as possible to promote self-distancing while allowing more space for children to move around (American Academy of Pediatrics 2020; Sick Kids Foundation 2020; Gill 2011; Maller 2009; Maller and Townsend 2006; O’Brien and Murray 2007).

Interestingly, some research suggests that learning environments go beyond the 'traditional classroom' in schools as children seem to engage in learning when exposed to outdoor activities or natural environments such as gardens, and/or perhaps backyards or playgrounds (American Academy of Pediatrics 2020; Gill 2011; Maller 2009; Maller and Townsend 2006; O’Brien and Murray 2007). Perhaps, teachers should consider the inclusion of such learning environments in their lesson planning as much as possible, whether during remote teaching or in-person schooling.

Secondly, parents suggest teachers to focus on interacting with students, perhaps using less technology resources while in school. The great majority of parents in this study argue that during the schools' closure, the interaction between the teachers and the students in public schools averaged an hour a week, much below the $2 \mathrm{~h}$ daily screen-time recommended limit for elementary school aged children (Martin 2011). However, some parents, who worked full- time and needed child-care in order to work, were forced due to pandemic socio-economic circumstances to allow their children more screen time. Several parents are concerned that their children might have mental health-related problems caused by overexposure to screen time (Martin 2011; Statistics Canada 2020).

Third, due to the uncertainty of this pandemic, another concern parents had was if another lockdown took place and schools were forced to implement a learning from home scenario (Alberta Education 2020a), they strongly point to the need for more interactions between teachers and students when using technology to learn from home (Martin 2011). One of the parents showed his/her frustration with schools, especially teachers for not properly utilizing technology or online platforms to interact with students and further support learning by saying that 'home is not an ideal environment for children to learn'(focus-group). This parent implied that 'parents are not teachers and home is not a school'.

Even though parents agree that online interactions are not as effective as inperson, the lack of social interactions all together especially among young children can lead to the development of mental health issues (DeSocio and Hootman 2004). Some parents were very frustrated with what they perceived as a disconnection between the teachers and the students, suggesting that an hour or less a week of online teacher-student interaction is not enough to support learning from home, and contributed to an increase of the stress level of parents, and especially children (Lacey et al. 2014; Makinodan et al. 2012; Matthews et al. 2015). A reflection on the 
effectiveness of educational practices implemented during the school closure will be hopefully addressed by future studies.

Lastly, these parents also suggest improving relationships and communication between school and parents (Amaral 2007; Sedibe and Fourie 2017). These parents advocate that schools should function more like an interconnected entity where the needs of parents, who are key to support learning from home even though many of them do not speak French, are also taken into consideration. Some parents were very emotional as they spoke of their experiences and the pressure they felt due to the role that was imposed as they became non-official teacher aides together with the associated lack of communication and support from schools, especially teachers and administrators as well as school boards.

In terms of implications, this case study is significant not only for students in French Immersion programs but also to bring attention to the mental health of all elementary school-aged children. Even though further studies are currently still in their early stages or nonexistent in different parts of the world, my assumption is that due to challenging socio-economic issues and the lack of access to technology, parents' lack of familiarity with technology will be highlighted in many future studies. This study, in particular, is important because in this case, the lack of technology was not a concern among the participants, which may lead to further investigation of questions such as what happens when the lack of technology and the ability to use it are not a factor in students' success learning from home? What are the remaining challenges for parents supporting teaching from home?

This study might also have implications for educational policies, school boards, and teacher preparation programs as well as professional development practices by enhancing the mutually beneficial relationships developed between parents and teachers.

\section{Conclusions}

The mental health of both parents and students is a concern to education due to the uncertainty surrounding this unprecedented time that people worldwide are experiencing, mainly caused by the COVID-19 pandemic (American Academy of Pediatrics 2020; John Hopkins University and Medicine 2020). Parents are extremely apprehensive about the near future as schools are supposed to open in September 2020 (Alberta Education 2020a). However, the instability of the rate of COVID-19 infections can impact educational plans, and there is always a possibility of parents going through this 'homeschooling' process again.

The parents in this study wanted to voice their experiences and their insights on how we can improve the experiences of children at home as well as make teachers and educational authorities aware of the difficulties, especially related to mental health, their children might have with the transition back to school and adapting to the new social distancing norms in place to prevent the spread of new infections in schools.

In a nutshell, as schools are a community of learners, the mental health of parents, teachers, and students, as well as administrators, should be meaningfully taken 
into consideration by all levels of education as this pandemic crisis has affected everyone in schools (Fontenelle-Tereshchuk 2020; Gray et al. 2017).

\section{References}

Alberta Education. (2020a). 2020/2021 Schools re-entry plan. Retrieved from https://open.alberta.ca/ dataset/a3910dd5-d52f-4a7d-821f-a381002419e9/resource/d50970dc-e060-4470-9f7b-0028ff3621 36/download/edc-covid-2020-2021-school-re-entry-plan-updated-2020-07-21.pdf

Alberta Education. (2020b). Retrieved from https://www.alberta.ca/french-language-education-in-alber ta.aspx\#toc-0

Alberta Government. (2020). Retrieved from https://www.alberta.ca/covid-19-alberta-data.aspx?utm_ source=google\&utm_medium $=$ sem\&utm_campaign $=$ Covid $19 \& u t m \_t e r m=$ data\&utm_conte $\mathrm{nt}=\mathrm{v} 1 \& \mathrm{gclid}=$ EAIaIQobChMI-9Xkh4nh6gIV1B-tBh2H_QJKEAAYASAAEgJn7fD_BwE

Amaral, D. M. (2007). Parents' perspectives: The role of parents in the education of children. Retrieved open.library.ubc.ca:ubc_2007-317280

American Academy of Pediatrics (2020). Retrieved from https://services.aap.org/en/pages/2019-novel -coronavirus-covid-19-infections/clinical-guidance/covid-19-planning-considerations-return-to-inperson-education-in-schools/\#.XwyRyIKm27M.email

Creswell, J. W. (2012). Educational research: Planning, conducting, and evaluating quantitative and qualitative research (4th ed.). Boston, MA: Pearson.

DeSocio, J., \& Hootman, J. (2004). Children's Mental Health and School Success. The Journal of School Nursing, 20(4), 189-196.

Fontenelle-Tereshchuk, (2020). Diversity in the classrooms: A human-centered approach to schools. Interchange Journal. https://doi.org/10.1007/s10780-020-09402-4.

Gray, C., Wilcox, G., \& Nordstokke, D. (2017). Teacher mental health, school climate, inclusive education and student learning: A review. Canadian Psychology/Psychologiecanadienne, 58(3), 203-210.

Gill, T. (2011). Children and nature: A quasi-systematic review of the empirical evidence. the London Sustainable Development Commission. Retrieved from https://www.london.gov.uk/sites/default/ files/lsdc_-_sowing_the_seeds_-_literature_review_2011.pdf

Holloway, D., Green, L., \& Livingstone, S. (2013). Zero to eight: Young children and their Internet use. London, England: EU Kids Online. Retrieved from https://eprints.lse.ac.uk/52630

John Hopkins University \& Medicine. (2020). Retrieved from https://coronavirus.jhu.edu/map.html

Lacey, R. E., Kumari, M., \& Bartley, M. (2014). Social isolation in childhood and adult inflammation: Evidence from the National Child Development Study. Psychoneuroendocrinology, 50, 85-94.

Livingstone, S. (2019). EU kids online. The International Encyclopedia of Media Literacy. https://doi. org/10.1002/9781118978238.ieml0065.

Maller, C., \& Townsend, M. (2006). Children's mental health and wellbeing and hands-on contact with nature. International journal of learning, 12(4), 359-372.

Maller, C. J. (2009). Promoting children's mental, emotional and social health through contact with nature: A model. Health Education., 109(6), 522-543.

Makinodan, M., Rosen, K. M., Ito, S., \& Corfas, G. (2012). A critical period for social experiencedependent oligodendrocyte maturation and myelination. Science, 337(6100), 1357-1360.

Martin, K. (2011). Electronic overload: The impact of excessive screen use on child and adolescent health and wellbeing. Perth, WA: Department of Sport and Recreation.

Matthews, T., Danese, A., Wertz, J., Ambler, A., Kelly, M., Diver, A., et al. (2015). Social isolation and mental health at primary and secondary school entry: A longitudinal cohort study. Journal of the American Academy of Child and Adolescent Psychiatry, 54(3), 225-232. https://doi.org/10.1016/j. jaac.2014.12.0080.

Morris, J., \& Zidenberg-Cherr, S. (2002). Garden enhanced nutrition education curriculum improves fourth-grade school children's knowledge of nutrition and preferences for some vegetables. Journal of American Dietetic Association, 102(1), 91-93.

O'Brien, L., \& Murray, R. (2007). Forest School and its impacts on young children: Case studies in Britain. Urban Forestry \& Urban Greening, 6, 249-265.

Ozdemir, A., \& Yilmaz, O. (2008). Assessment of outdoor school environments and physical activity in Ankara's primary schools. Journal of Environmental Psychology, 28(3), 287-300. 
Sedibe, M., \& Fourie, J. (2017). Exploring opportunities and challenges in parent-school partnerships in special needs schools in the Gauteng Province, South Africa. Interchange, 2018(49), 433-444. https ://doi.org/10.1007/s10780-018-9334-5.

Sick Kids Foundation. (2020). COVID-19: Recommendations for School Reopening. Retrieved from https://www.sickkids.ca/PDFs/About-SickKids/81497-COVID19-Recommendations-for-Schoo 1-Reopening-SickKids-JUNE.pdf

Statistics Canada. (2020). Impacts of COVID-19 on Canadians: Parenting during the pandemic ISBN: 978-0-660-35358-6.

Varela, A. D., Kelcey, J., Reyes, J., Gould, M., \& Sklar, J. (2013). Learning and resilience : The crucial role of social and emotional well-being in contexts of adversity (English). Education notes Washington, D.C.: World Bank Group. Retrieved from https://documents.worldbank.org/curated/en/84999 1468337162828/Learning-and-resilience-the-crucial-role-of-social-and-emotional-well-being-incontexts-of-adversity

Yin, R. K. (2009). Case study research: Design and methods (4th ed.). Thousand Oaks, CA: Sage.

World Health Organization. (2019). The WHO special initiative for mental health (2019-2023): Universal health coverage for mental health. World Health Organization. Retrieved from https://apps.who. int/iris/handle/10665/310981.

Wu, Q., Xing, Y., Shi, L., Li, W., Gao, Y., Pan, S., et al. (2020). Coinfection and other clinical characteristics of COVID-19 in children. Pediatrics, 146(1), 1-9. https://doi.org/10.1542/peds.2020-0961.

Publisher's Note Springer Nature remains neutral with regard to jurisdictional claims in published maps and institutional affiliations. 